\title{
Knowledge, Attitude, Practices, and Factors Associated with Voluntary Blood Donation among Graduating Class Students of Assosa University, Benishangul Gumuz, Ethiopia, 2018
}

\author{
Ayenew $\mathrm{BA}^{1 *}$ and Adulla $\mathrm{MA}^{2}$ \\ ${ }^{1}$ Department of Nursing, Assosa University, Ethiopia \\ ${ }^{2}$ Department of Public Health, Assosa University, Ethiopia
}

*Corresponding author: Birhanu Ayenew Anleye, Department of Nursing, Health Science College, Assosa University, Assosa, Ethiopia, P.O box 18, Tel: +251919562770; Email: mulugetaadmsau@gmail.com

\section{Research Article}

Volume 4 Issue 1

Received Date: March 09, 2020

Published Date: March 26, 2020

DOI: $10.23880 / \mathrm{hij}-16000155$

\section{Abstract}

Background: Blood transfusion is a vital therapeutic approach in modern health care that saves millions of lives, but there is a great challenge to gate sufficient voluntary blood donation in developing country like Ethiopia at the same time pregnancy and child birth related problem, rod traffic accident, malaria-related death is high.

Methods: Institutional based cross-sectional quantitative study was used from April 27 to May 11, 2018, and data was collected using a self-administered questionnaire. A stratified sampling method was used and an individual was selected by simple random sampling within each stratum. EPI data version 3.02 for data entry and SPSS version 16 for analysis was used both bi-variant and multi-variant analysis was computed and significance was declared at AOR $<0.05$.

Results: From the total study participants, 162(48.5\%) had adequate knowledge, 230(68.9\%) of the respondent had favorable attitudes towards blood donation whereas only 85 (25.4\%) have ever donated blood in their lifetime. Having inadequate knowledge 3.118 times more likely non-donors [AOR=3.118: 1.775, 5.479] than compared to those having adequate knowledge, and unfavorable attitude 4.254 times non-donors [AOR $=4.254 \% \mathrm{CI}: 1.996,9.069$ ] than compared to those having a favorable attitude. Whereas being a user of television 2.015 times more likely non-donors of blood [AOR=2.015 \%CI: 1.100 , 3.690] than compared to non-user.

Conclusion: the result shows that there was poor habit of blood donation practice among students and even from donors above the mean range $57.6 \%$ of respondent donate blood to help relatives or friends and we recommend further study in this area, to give training for blood bank service workers and organize motivational blood donor club to utilize potential voluntary blood donors.

Keywords: Blood donation; Emergency health care; Assosa; Benishangul Gumuz; Assosa University

Abbreviations: KAP: Knowledge, Attitude, Practice; KAMC: King Abdul-Aziz Medical City.

\section{Introduction}

Blood transfusion is an essential component of health care, the key life-saving interventions, which saves millions of lives $[1,2]$ each year, every second someone in the world needs blood for surgery, trauma, severe anemia or complications of pregnancy, [1] generous blood donors are the only source of blood for a patient that needs blood transfusions, [3] there no substitute for it, it be mead or manufactured [4]. 


\section{Haematology International Journal}

Every day, almost 800 women die related to complications of pregnancy and childbirth [2] worldwide ever year 1.35 million people die as a result of a road traffic crash, at the same time $93 \%$ of the world's fatalities on the roads occur in low- and middle-income countries [5]. Road traffic injury death rates are highest in the African, including Ethiopia which is ranked the 6th cause of death According to the latest WHO data published in 2017 [6]. Road traffic injuries are predicted to become the third-largest contributor to the global burden of disease by 2020 [7]. Urgent access to safe supplies of blood for transfusion is critical to saving these women's lives.

Despite WHO recommend 100\% Voluntary NonRemunerated Donation of Blood and blood components to every patient as the need should be available in each health facility, In many countries, family members are often pressured to donate blood or find a replacement donor in an emergency [8]. This causes emotional and financial stress and significant delays in obtaining suitable blood and also puts women at risk of blood-borne infections as there is often no time or facilities to properly screen the donated blood.

University students are expected to be more aware than the general population towards voluntary blood donations among the population. They also considered as a potential pool of eligible voluntary donors and motivators, so, keeping in view, of the significance of blood donation and transfusion is important, but there is no research conducted before in our area and this study was conducted to see the KAP and factors associated with voluntary blood donation among graduating class students would be helpful to identify the gaps and implement appropriate strategies among responsible sectors.

\section{Materials and Methods}

The institution-based cross-sectional study design was used to assess knowledge, attitude, practice, and associated factors towards voluntary blood donation among graduating class students of Assosa University in 2018. Assosa city was founded in 1936. It is the capital city of Benishangul Gumuz regional state that is located about $666 \mathrm{~km}$ western of Addis Ababa (the capital city of Ethiopia), $96 \mathrm{~km}$ from ethio_sudan border, and $230 \mathrm{~km}$ from Ethiopian millennium Renaissance Dam. Assosa University is the only university within the Benishangul Gumuz region and founded in 2004/2011GC. There are 7 faculties and 1 school of law and have 36 departments under the university in the academic year of 2018. This study was conducted from April 27 to May 11, 2018.

The study population included all graduating class students attending in Assosa University in 2018. Students not available in time of data collection period and students who are critically ill on the days of the data collection period were excluded from this study. Socio-demographic characteristics (Age, Sex, Religion, department, residence, and use of social Media) among study participants were used as an independent variable. Whereas Knowledge, attitude, and practice towards voluntary blood donation among graduating class students were the dependent variable.

The sample size was determined by using a single proportion formula based on the prevalence from the previous study conducted in samara university using 54\% for knowledge level, using 95\% confidence interval level $(\mathrm{Z} \alpha / 2=1.96)$ and absolute precision or margin of error to be $5 \%(\mathrm{~d}=0.05)$.

The sample size required was 346 after considering a $10 \%$ non-response rate. The study participant was selected using, first graduating class students were stratified based on their college/faculty/ and proportionally allocated for each stratum, and the sample was drawn by using simple random sampling technique (lottery method) based on the students' identification number (ID NO) (Figure 1). Data collection was done by pre-tested, pre-coded, and self- administered questionnaire with open and closed-ended questions. This structured questionnaire adapted from similar previous studies on $[9,10]$ literature and a questionnaire that was modified to the study setting. Pre-testing of the questionnaire was performed on $17(5 \%)$ students from the total sample size on Polly Professional technique college students before one week of actual data collection (Figure 1).

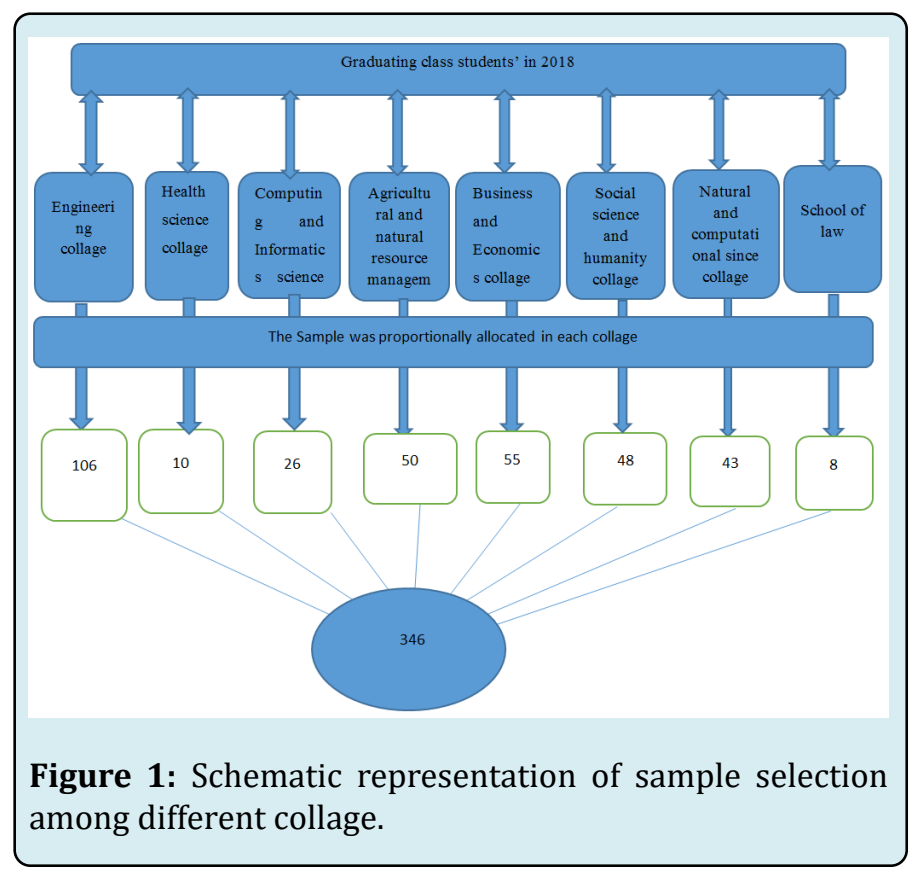




\section{Haematology International Journal}

Supervision conducted by two principal investigators, finally data were checked for consistency and completeness before analysis. The questionnaire is originally prepared in English language and then translated to Amharic and again retranslated to English by language experts for consistency and both of them was given to the study participants

Data were entered with EPI data version 3.02 to minimize data entry error and final data was export to SPSS version 16 for data analysis. The data wound was presented by using table and bar graph after analysis. Frequency distributions, cross-tabulations, and graphs were used to describe the variables under the study. Binary logistic regression analysis was used to examine the association between the independent variables and dependent variables. All variables with $\mathrm{p}$-value $<0.2$ in bivariate analysis were entered into the final multiple logistic regression model to identify variables independently associated with KAP towards blood donation. The backward stepwise likelihood ratio was used to select the final independent predictors with a 95\% confidence interval. The significance of the Adjusted Odds Ratio (AOR) was declared at $\mathrm{p}$-value $<0.05$.

According to the literature $[9,10]$ on this operational definition was taken to make measurable our study.

a) Knowledge: From the major questions on the knowledge part, each of those who have answered above the 50th percentile (out of 23quetionnaire, who answered 13and above) of the score were considered to be having adequate knowledge. The rest were categorized as insufficient knowledge.

b) Attitude: Respondents who answered above the mean range (out of 9 questionnaires, who answered 5 and above) correctly will be considered as favorable attitude. Those individuals who gave a correct answer below the mean range will be considered as an unfavorable attitude towards blood donation. Practice individuals experienced blood donation activity at least once in their lifetime will be considered as having practice.

c) Voluntary donors: Those individuals who donate blood without receiving payment or a replacement for family or friends, but only for an internally generated sense of altruism or community responsibility.

The ethical review and approval commute of health Science College, Assosa University approved the study for its ethical and scientific merit. Informed verbal consent was also obtained from the respective students for their participation after the nature of the study was fully explained in their local languages. The right to withdraw from the study at any time was also communicated and respected. And also the confidentiality of information was maintained in each level of the response including omitting personal identifiers such as the name and identification number or ID No of participants.

\section{Results}

\section{Socio-Demographic Characteristics}

A total of 334 (96.5\%) graduating class students were participated from 346 of the proposed sample size with a non-response rate of $3.5 \%$ due to un-availability on time of data collection. Concerning sex composition of study participants, 181(54.2\%) of them were male and 153 $(45.8 \%)$ were female and the mean age of the respondent was 23.02 years old which ranges from 20 to 30 years. Regarding religion 222(66.5\%) of the respondents were Orthodox followed by Muslim and protestant 58 (17.4\%) and $51(15.3 \%)$ respectively and others $3(0.9 \%)$.

Almost all of the respondents 318(95.2\%) were familiar and use social media. Among 8 collage, the proportion of engineering collage was highest which accounts, 99 (29.6\%) compared to the school of law $10(2.4 \%)$ were included in this study which was directly proportional to the source population (Table 1).

\begin{tabular}{|c|c|c|}
\hline Variable & Frequencies & Percentage \% \\
\hline Age & & $91.30 \%$ \\
\hline $18-25$ & 305 & $8.70 \%$ \\
\hline $26-35$ & 29 & 54.2 \\
\hline Sex & & 45.8 \\
\hline Male & 181 & \\
\hline Female & 153 & 29.6 \\
\hline Collage of respondent & & \\
\hline Engineering collage & 99 & \\
\hline
\end{tabular}




\begin{tabular}{|c|c|c|}
\hline Health since collage & 10 & 3 \\
\hline Agricultural collage & 48 & 14.4 \\
\hline Business and economics collage & 52 & 15.6 \\
\hline Social science and humanity collage & 46 & 14.4 \\
\hline School of law & 8 & 2.4 \\
\hline Natural and computational collage & 43 & 12.9 \\
\hline Computing and informatics collage & 26 & 7.8 \\
\hline \multicolumn{3}{|l|}{ Religion } \\
\hline Orthodox & 222 & 65.5 \\
\hline Muslim & 58 & 17.4 \\
\hline Protestant & 51 & 15.3 \\
\hline Other & 3 & 0.9 \\
\hline \multicolumn{3}{|l|}{ Where are you come /Residence } \\
\hline Urban & 152 & 45.5 \\
\hline Rural & 182 & 54.5 \\
\hline \multicolumn{3}{|l|}{ Are you use social media } \\
\hline Yes & 318 & 95.2 \\
\hline No & 16 & 4.8 \\
\hline \multicolumn{3}{|l|}{ Which type of social media } \\
\hline Internet & 236 & 74.2 \\
\hline Television & 105 & 33 \\
\hline Radio /FM & 109 & 34.2 \\
\hline Newspaper & 47 & 14.8 \\
\hline Others $^{\$ \$}$ & 2 & 0.6 \\
\hline
\end{tabular}

Other\$= wake feta, catholic. Other\$ $\$=$ film

Table 1: Socio-demographic characteristics of graduating class students in Assosa University in 2018.

\section{Knowledge of Study Participants towards Voluntary Blood Donation}

In this study, 162(48.5\%) had adequate knowledge of blood donation. Among the study participants, 255(76.3\%) know about the common blood group, from this one hundred forty-three $56.1 \%$ of them get information from the classroom followed by on internet $119(46.6 \%)$. Around $241(72.2 \%)$ of respondents know the medical benefit of VBD and three forth 223 (66.8\%) of them say no human blood manufactured artificially in the laboratory. But only $127(38.0 \%)$ of respondents know the minimum time interval between two donations and $97(29.0 \%)$ of them know the volume of blood donation at a time.

\section{Factors Associated with Knowledge of Respondent about Voluntary Blood Donation}

This study revealed that the level of good knowledge towards blood donation among graduating class students age, sex, religion, residence, and newspaper redder didn't show any significant in bivariate analysis (p-value $>0.2$ ) and didn't include in the multi-variant analysis. Also, collage of study, use of social media, television user, and radio/FM users show significant association in bi-vibrant but not in multi-variant analysis. Multiple logistic regression analysis factors significantly predictive level of knowledge of blood donation among internet users. Bing non-user of the internet was 1.764 times more likely [AOR $=1.764,95 \%$ CI: 1.029 , 3.026] having inadequate knowledge than when compared to the internet user (Table 2). 


\begin{tabular}{|c|c|c|c|c|c|}
\hline \multirow[t]{2}{*}{ Variable } & \multicolumn{5}{|c|}{ Overall knowledge } \\
\hline & $\begin{array}{l}\text { Inadequate } \\
\text { knowledge }\end{array}$ & $\begin{array}{c}\text { Adequate } \\
\text { knowledge }\end{array}$ & $\operatorname{COR}(95 \% \mathrm{CI})$ & AOR(95\%CI) & P-value \\
\hline \multicolumn{6}{|l|}{ Collage/faculty } \\
\hline Engineering & 50 & 49 & 1 & & \\
\hline Health since & 1 & 9 & $0.109(0.013,0.892)$ & $\mathrm{z}$ & $\mathrm{Z}$ \\
\hline Agricultural & 30 & 18 & $1.633(0.807,3.305)$ & $\mathrm{z}$ & \\
\hline Business and & \multirow{2}{*}{26} & \multirow{2}{*}{26} & \multirow{2}{*}{$0.980(0.501,1.918)$} & \multirow{2}{*}{$\mathrm{z}$} & \\
\hline economics & & & & & \\
\hline Social science and & \multirow{2}{*}{21} & \multirow{2}{*}{27} & \multirow{2}{*}{$0.762(0.381,1.524)$} & \multirow{2}{*}{$\mathrm{z}$} & \\
\hline humanity & & & & & \\
\hline School of law & 4 & 4 & $0.980(0,232,4.140)$ & $\mathrm{z}$ & \\
\hline Computing and & \multirow{2}{*}{14} & \multirow{2}{*}{12} & \multirow{2}{*}{$1.143(0.481,2.718)$} & \multirow{2}{*}{$\mathrm{z}$} & \\
\hline informatics & & & & & \\
\hline Natural and & \multirow{2}{*}{26} & \multirow{2}{*}{17} & \multirow{2}{*}{$1.499(0.724,3.102)$} & \multirow{2}{*}{$\mathrm{z}$} & \\
\hline computational & & & & & \\
\hline \multicolumn{6}{|l|}{ Use of social media } \\
\hline Yes & 159 & 159 & 1 & & $\mathrm{Z}$ \\
\hline No & 13 & 3 & $4.333(1.211,15.500)$ & $\mathrm{Z}$ & \\
\hline \multicolumn{6}{|l|}{ Internet user } \\
\hline yes & 108 & 128 & 1 & 1 & $0.039 * * *$ \\
\hline No & 51 & 31 & $1.950(1.165,3.262)$ & $1.764(1.029,3.026)$ & \\
\hline \multicolumn{6}{|l|}{ Television user } \\
\hline Yes & 47 & 58 & 1 & & $\mathrm{Z}$ \\
\hline No & 112 & 101 & $1.368(0.856,2.188)$ & $\mathbf{z}$ & \\
\hline \multicolumn{6}{|l|}{ Radio/FM user } \\
\hline yes & 63 & 46 & 1 & & $\mathrm{Z}$ \\
\hline No & 96 & 113 & $0.620(0.389,0.990)$ & $\mathrm{z}$ & \\
\hline
\end{tabular}

$\mathrm{Z}=$ factors associated in bi-variant but not in multi-variant analysis. ${ }^{* * *}=$ variables show significant association on both bi vibrant and multi variant analysis

Table 2: factors associated with knowledge level of graduating class students towards blood donation in 2018.

\section{The Attitude of the Study Participants towards Voluntary Blood Donation}

Among the overall respondents $207(62.0 \%)$ said blood donation is good habit, $79(23.6 \%)$ of them thinks bad and $48(14.4 \%)$ of them say no idea. Around the mean range $168(50.3 \%)$ of study participants respond as voluntary blood donation is the best source of blood donation. The overall attitude of individuals towards voluntary blood donation was assessed by summing up the correct answers of individual questions and from the total participant three fourth $230(68.9 \%)$ of the respondent had favourable attitude towards blood donation whereas 104(31.1\%) unfavourable attitude.

\section{Factors Associated with Attitude towards Voluntary Blood Donation}

In bivariate logistic regression age, internet user, and level of knowledge were shows significantly associated with the attitude of the participants towards VBD, while in multivariate logistic regression internet user doesn't 
significantly associate with VBD. When you see the level of knowledge, inadequate knowledge, was 2.098 times having an unfavorable attitude towards VBD (AOR $=2.098,95 \% \mathrm{CI}$ : $1.281,3.437)$ when compared to having adequate knowledge and. Also, Bing increases the age of respondents from 26-35 was 2.393 times having an unfavorable attitude $(\mathrm{AOR}=2.393$, 95\% CI: 1.051, 5.449) towards VBD when compared with age between 18-25 (Table 3).

\begin{tabular}{|c|c|c|c|c|c|}
\hline \multirow[t]{2}{*}{ Variable } & \multicolumn{5}{|c|}{ Overall Attitude } \\
\hline & Unfavorable attitude & Favorable attitude & $\operatorname{COR}(95 \% \mathrm{CI})$ & AOR(95\%CI) & P-value \\
\hline \multicolumn{6}{|l|}{ Age } \\
\hline $18-25$ & 89 & 216 & 1 & 1 & \multirow{2}{*}{$0.048^{* * *}$} \\
\hline $26-35$ & 14 & 15 & $2.600(1.205,5.611)$ & $2.393(1.051,5.449)$ & \\
\hline \multicolumn{6}{|l|}{ Internet user } \\
\hline yes & 66 & 170 & 1 & & \multirow{2}{*}{$\mathbf{z}$} \\
\hline no & 31 & 51 & $1.566(0.922,2.658)$ & & \\
\hline \multicolumn{6}{|l|}{ Level of knowledge } \\
\hline Adequate knowledge & 37 & 125 & 1 & 1 & \multirow[b]{2}{*}{$0.003^{* * *}$} \\
\hline $\begin{array}{l}\text { In adequate know } \\
\text { ledged }\end{array}$ & 67 & 105 & $2.156(1.337,3.477)$ & $2.098(1.281,3.437)$ & \\
\hline
\end{tabular}

$\mathrm{Z}=$ factors associated in bi-variant but not in multi-variant. ${ }^{* * *}=$ variables show significant association on both bi vibrant and multi variant analysis

Table 3: factor associated with attitude of among study participant towards VBD in 2018.

\section{The Practice of Blood Donation towards Voluntary Blood Donation}

Among the total participant of graduating class students, only around one quarter, 85 (25.4\%) have ever donated blood and of these $53(62.4 \%)$ of donors had donated blood once in their lifetime, 19 (22.4\%), 9(10.6\%), and $4(4.7 \%)$ of them donate blood twice, three times and four times, but no one donor donate blood either regularly or greater than four times. Regarding reasons that motivate for blood donation, greater than the mean range, $49(57.6 \%)$ of the total donors said that donation could be for helping relatives or friends.

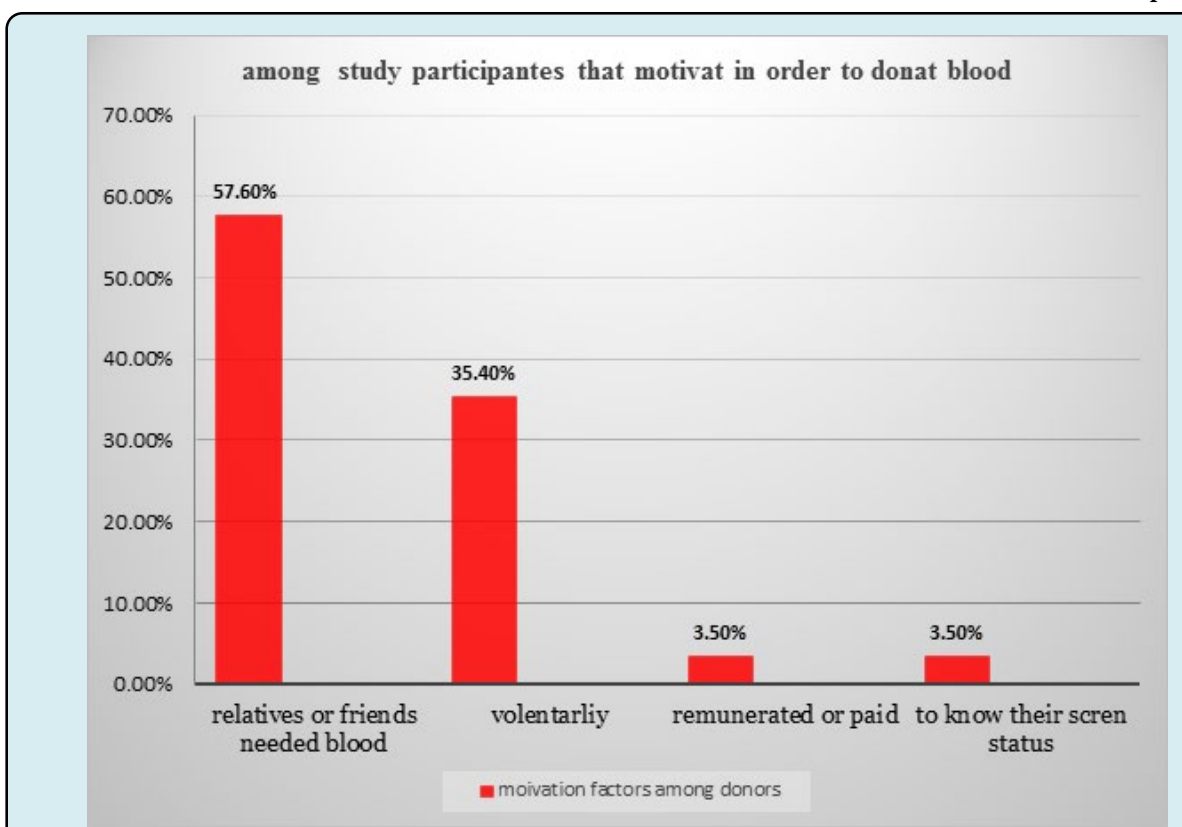

Figure 2: Motivational factors among blood donors in order to donate blood. 


\section{Haematology International Journal}

From donors, the majority 77(90.6\%) of them were satisfied to do so. Concerning reasons for non-donating among non-donors $249,112(45.0 \%)$ of them side fear of knowing their screen status followed by $106(42.6 \%)$ of them side donated blood may be sold were mentioned as major reasons for not donating blood. Satisfactorily majority of study participants $263(78.7 \%)$ of them were having the interest to donate blood in the future. We can see Details from Figure 2 about the reason that makes study participants do donate blood.

\section{Factors Associated with Voluntary Blood Donation Practice}

The likelihood of blood donation in bi-variant analysis Sex, age, religion, the residence where you come, and collage (field of study) didn't show significance association towards VBD practice ( $\mathrm{p}$-value $>0.2$ ) and didn't include from a multivariate regression analysis. A multivariate analysis on blood donation practice revealed that a statistically significant association with television user, attitude and knowledge level of respondent. Being a user of television 2.015 times more likely non-donors of blood [AOR=2.015, 95\% CI: 1.100 , 3.690] than compared to non-user but internet and radio / FM user didn't show statistically significant association with VBD. When you compared to the knowledge and attitude towards practice, both having inadequate knowledge 3.118 times non-donors [AOR=3.118, 95\% CI: 1.775, 5.479], and unfavorable attitude 4.254 times non-donors [AOR=4.254, 95\% CI: $1.996,9.069]$ than compared to those adequate knowledge and favorable attitude respectively (Table 4).

\begin{tabular}{|c|c|c|c|c|c|}
\hline \multirow{2}{*}{ Variable } & \multicolumn{5}{|c|}{ Blood donation practice } \\
\hline & Non-donor & donor & COR(95\%CI) & AOR(95\%CI) & p-value \\
\hline \multicolumn{6}{|l|}{ Internet user } \\
\hline Yes & 170 & 66 & 1 & & $\mathbf{z}$ \\
\hline No & 65 & 17 & $1.484(0.811,2.718)$ & $\mathbf{z}$ & \\
\hline \multicolumn{6}{|l|}{ Television user } \\
\hline Yes & 85 & 20 & $1.785(1.010,3.153)$ & $2.015(1.100,3.690)$ & $0.023^{* * *}$ \\
\hline No & 150 & 63 & 1 & 1 & \\
\hline \multicolumn{6}{|l|}{ Radio/FM user } \\
\hline Yes & 88 & 21 & $1.767(1.009,3.097)$ & & $\mathbf{z}$ \\
\hline No & 147 & 62 & 1 & $\mathbf{z}$ & \\
\hline \multicolumn{6}{|l|}{ Level of knowledge } \\
\hline Adequate knowledge & 103 & 59 & 1 & 1 & $0.000^{* * *}$ \\
\hline In adequate know ledged & 146 & 26 & $3.217(1.901,5.442)$ & $3.118(1.775,5.479)$ & \\
\hline \multicolumn{6}{|l|}{ Attitude of respondent } \\
\hline Favorable attitude & 154 & 76 & 1 & 1 & $0.000^{* * *}$ \\
\hline Unfavorable attitude & 95 & 9 & $5.209(2.494,10.882)$ & $4.254(1.996,9.069)$ & \\
\hline
\end{tabular}

$\mathrm{Z}=$ factors associated in bi-variant but not in multi-variant. ${ }^{* *}=$ variables show significant association on both bi vibrant and multi variant analysis

Table 4: Factors associated with practice of voluntary blood donation among graduating class students in 2018.

\section{Discussion}

One of the visions of WHO by 2020 counters to achieve $100 \%$ voluntary non-remunerated blood donation in every country of the world but concurrently, blood donor recruitment becomes more difficult and a global issue particularly in developing countries at the same time the demand for blood products steadily increases. Therefore, understanding the level of knowledge, attitude, practice, and associated factor towards voluntary blood donation is essential and this study found out the level of Knowledge, Attitude, Practice (KAP) with respective of associated factors towards voluntary blood donation among graduating class students in Assosa University.

In this study, 162(48.5\%) had adequate knowledge towards blood donation which is less knowledgeable than compared study conducted Samara university health science student which is $54 \%$, health science students of Addis Ababa University 121 (83.7\%), and study conducted 


\section{Haematology International Journal}

at Nigeria which is $64.8 \%$ of the respondents had good knowledge about blood donation [11-13] respectively. This might be due to the study population difference. The previous study conducted only health science, students. But in our study, participants selected from both health and nonhealth since students. The current study revealed that the level of knowledge towards voluntary blood donation was higher when you compared to study conducted among Ambo university about 161 (40.4\%) had good knowledge [10] and study conducted in bachelor level students in Nepal which were average score was $32.01 \%$ had good knowledge about blood donation [14]. This might be due to time and sociodemographic difference respectively. Ambo university study was conducted in 2014 and In this study 223 (66.8\%) of respondent say no human blood manufactured artificially in the laboratory that means answered correctly which is higher study conducted in India college students of both health and non-health science students $40(63 \%)$ of health science student respond "no artificial blood" i.e. has good knowledge about artificial and 88(59.9\%) of non-health students think that there is artificial blood available [15]. This might be due to socio-demographic differences.

And also in this study, only $97(29.0 \%)$ of them know the volume of blood donation which is less than compared to study conducted in samara university health science student $(54.6 \%)$ of individuals know the volume of blood donated during each donation and study conducted Addis Ababa university (8.6\%) of respondents didn't know the maximum amount of blood to be donated respectively $[9,12]$. This might be due to study population difference. The previous study conducted only health science, students. But study participants selected from both health and non-health science students.

From the total participant, three fourth $230(68.9 \%)$ of the respondent had favorable attitude towards blood donation which is almost similar with study conducted in Addis Ababa university $68 \%$ of the participants had favorable attitude [12] and study conducted in samara university health science student which is $65.8 \%$ of respondents $(61.0 \%-71.0 \%)$ had favorable attitude towards VBD(9)This study was higher than study conducted in ambo university student which is $189(47.4 \%)$ had positive attitude towards voluntary blood donation with the $95 \%$ CIof $42.4 \%$ to $52.4 \%(13)$ and study conducted in two public and one private medical college in Karachi, Pakistan which is $252(42.00 \%)$ had positive attitude towards blood donation [16]. This might be due to time, social, and cultural deference among study participants respectively. And at the same time, this study was higher than the study conducted in Debre-Markos 403(52.2\%) of respondents had a favorable attitude towards blood donation [17]. But the result of this study less than the study conducted in Gondar town which is $630(82 \%)$, of the respondents had a good attitude towards blood donation [18]. This difference may be due to the study population difference. Both studies were conducted at Gondar and Debre-Markos town which was at the community level but this study was conducted among graduating class students.

Among the total participant of graduating class students, only around one quarter, 85 (25.4\%) have ever donated blood which is almost similar in study conducted in Addis Ababa University 90(23.4\%) have ever donated blood [12] and study conducted ambo university which is $94(23.6 \%)$ of the study participants were donated blood at least one times [10]. But this study was less compared to study conducted samara university health science students which is 252 (32.6\%) has ever donated blood at least once in their lifetime [11]. This might be due to knowledge and attitude difference of study population difference. The previous study conducted only health science, students. But in our study, participants selected from both health and non-health since students.

This study showed that the frequency of blood donation was 53(62.4\%) of donors had donated blood once in their lifetime among the total donor, $19(22.4 \%), 9(10.6 \%)$, and $4(4.7 \%)$ of them donate blood twice, three times and four times respectively which is higher than study conducted from 216 university students of medial income country which is $10 \%$ had donated for once, $8.5 \%$ two times, $1 \%$ three times, $1.5 \%$ four times [19]. This might be due to study population coverage which means the previous study conducted on medial income counters that include different counters but this study conducted only among graduating class students of Assosa University.

In this study showed that no one donor donate blood five times or more which is less than study conducted from 216 university students of medial income country which is $2.5 \%$ at least five times [19] and study conducted in Addis Ababa university students which are 38(42.2\%) of them were a regular donor [12]. This might be due to difference sociodemographic characteristics of study population.

Concerning reasons for non-donating among nondonors 249, 112(45.0\%) of them side fear of knowing their screen status followed by 106(42.6\%) of them side donated blood may be sold were mentioned as major reasons for not donating blood which is differ from study conducted at King Abdul-Aziz Medical City (KAMC) in Saudi Arabia which is more than half of them (52.4\%) mentioned that blood donation did not think in their minds and $45 \%$ mentioned that they had no time for donation while $41.3 \%$ mentioned that they had difficulty in accessing blood donation center as major reason [20]. And study conducted in ambo university which is 94(23.6)were due to fear or pain, $70(17.5 \%)$ were due to safety reasons [10], also study conducted in Addis 


\section{Haematology International Journal}

Ababa university student which is lack of information $68.4 \%$, not asked to donate $66.7 \%$ [12].

In this study, sex doesn't show any significant association with attitude on both bi-vibrant and multi-variant analysis which but it shows a significant study conducted in Addis Ababa University which is. Being male increased odds of favorable attitude AOR $(95 \% \mathrm{CI})=2.2(1.4,3.6)[12]$ this might be due to sex proportion of study population, this study was around men range. 181(54.2\%) of them were male and 153 $(45.8 \%)$ were female, both having inadequate knowledge 3.118 times non-donors [AOR=3.118, 95\% CI:: 1.775, 5.479], and unfavorable attitude 4.254 times non-donors [AOR=4.254, 95\% CI: 1.996, 9.069] than compared to those adequate knowledge and favorable attitude respectively which is almost similar study conducted in ambo university which is who had good knowledge were 2.96 times [AOR (95\%CI), 2.96(1.78-4.92)] more likely to be practice as compared to less knowledgeable respondents [10].

When you see the level of knowledge, inadequate knowledge, was 2.098 times having unfavorable attitude towards VBD (AOR= 2.098, 95\% CI: 1.281, 3.437) when you compared to having adequate knowledge which is almost similar when you compared to study conducted samara university health since students which is who had inadequate knowledge 0.45 times [AOR, (95\% CI), 0.45(0.258, 0.790)] less likely to had favorable attitude towards voluntary blood donation as compared to adequate knowledge [9] and study conducted in ambo university which is who had good knowledge 2.16 times [AOR, $(95 \% \mathrm{CI}), 2.16(1.4,3.35)$ more likely to had positive attitude towards voluntary blood donation as compared to less knowledge [10].

In this study, being a user of television 2.015 times more likely non-donors of blood [AOR $=2.015,95 \% \mathrm{CI}: 1.100$, 3.690] than compared to non-user. This finding supported by research conducted on blood donor's clinic of Delaware (BBD). According to this, psychological stress increased among television user than non-users and television users mainly concern game show, soap operas, commercials and resining or action movies, and no channel channels with continues news but no- television users are blank monitor and no sound [20].

\section{Conclusion}

This study revealed that there was a low incidence of blood donation practice in our study area even though WHO recommends this, being a user of the internet was significantly associated with having adequate knowledge towards blood donation. Having adequate knowledge and increasing the age of respondents were the independent predictors towards the favorable attitude of the respondent towards VBD. Having adequate knowledge, favorable attitude towards blood donation independent predictors of blood donation practice, also non-user of television increase blood donation practice more often so we recommend creating a regular promotion, organize mobile blood back service and further study on this area.

\section{References}

1. Organization WH (2008) Universal access to safe blood transfusion. Geneva: World Health Organization.

2. Team BTS, Organization WH (2006) World Blood Donor Day: "celebrating your gift of blood", 14 June 2005: stories from around the world.

3. Shi L, Wang JX, Stevens L, Ness P, Shan H (2014) Blood safety and availability: continuing challenges in China's blood banking system. Transfusion 54(2): 471-482.

4. Hußmann B, Lefering R, Taeger G, Waydhas C, Ruchholtz $S$, et al. (2011) Influence of prehospital fluid resuscitation on patients with multiple injuries in hemorrhagic shock in patients from the DGU trauma registry. J Emerg Trauma Shock 4(4): 465.

5. Organization WH (2018) Global status report on road safety 2018: Summary. World Health Organization.

6. Organization WH (2014) World health rankings: live longer live better. Online.

7. Lopez AD, Murray CC (1998) The global burden of disease, 1990-2020. Nature medicine 4(11): 1241-1243.

8. Organization WH (2010) Towards $100 \%$ voluntary blood donation: a global framework for action.

9. Misganaw C, Tenkir M, Deresa A, Tesfaye M, Tessema TT, et al. (2014) The level and associated factors of knowledge, attitude and practice of blood donation among health science students of Addis Ababa University. IJMHSR 1(10): 105-118.

10. Amatya M (2013) Study on knowledge, attitude and practice of blood donation among students of different colleges of Kathmandu, Nepal. Int J Pharm Biol Arch 4(3): 424-428.

11. Tadesse W, Ayalew Y, Yisma E, Liben ML, Wudu M (2018) Knowledge, Attitude, Practice and Associated Factors towards Voluntary Blood Donation among Regular Health Science Students of Samara University, Ethiopia. Health Science Journal 12(1): 542.

12. Salaudeen A, Odeh E (2011) Knowledge and behavior towards voluntary blood donation among students of a 


\section{Haematology International Journal}

tertiary institution in Nigeria. Nigerian journal of clinical practice $14(3)$ : 303-307.

13. Nigatu A, Demissie DB (2014) Knowledge, attitude and practice on voluntary blood donation and associated factors among Ambo University Regular Students, Ambo Town, Ethiopia. J Community Med Health Educ 4(5): 1-6.

14. Hada J (2008) A research report on knowledge, attitude and practice on blood donation among 18-25 years bachelor level people. Hope International College, pp: $1-30$.

15. Al Drees AM (2008) Attitude, belief and knowledge about blood donation and transfusion in Saudi population. Pak J Med Sci 24(1): 74-79.

16. Jemberu YA, Esmael A, Ahmed KY (2016) Knowledge, attitude and practice towards blood donation and associated factors among adults in Debre Markos town, Northwest Ethiopia. BMC Hematol 16(1): 23.
17. Melku M, Terefe B, Asrie F, Enawgaw B, Melak T, et al. (2016) Knowledge, attitude, and practice of adult population towards blood donation in Gondar Town, Northwest Ethiopia: a community based cross-sectional study. J Blood Transfusion.

18. Bourne P, Richards S, Holder-Nevins D (2013) Knowledge, attitude, practices and readiness among University Science Students Toward Non-Remunerated Blood Donation in a Middle-Income Developing Country. TAF Prev Med Bull 12(5): 529-538.

19. Alfouzan N (2014) Knowledge, attitudes, and motivations towards blood donation among King Abdulaziz Medical City population. Int J Family Medicine.

20. Ulrich RS, Simons RF, Miles MA (2003) Effects of environmental simulations and television on blood donor stress. J Architectural and Planning Research 20(1): 38-47. 